\title{
Fazer Teatro É Pensar o Teatro
}

CARREIRA ${ }^{1}$, André

\author{
..."[o pensamento é] tudo aquilo que se faz \\ em nós de tal modo que nos apercebemos \\ imediatamente por nós próprios." \\ Descartes, in Princípios de Filosofia.
}

Um dos maiores desafios para os artistas e pesquisadores é descobrir como se dá o diálogo entre o pensar e o fazer no que se refere aos processos de criação de espetáculos. Resulta mais fácil identificar a pesquisa que pode ser definida como acadêmica, ou teórica, quer dizer, aquela que supostamente está separada do fazer, ou é independente em relação ao fazer. No entanto, a pesquisa que está impregnada em nosso trabalho criativo é mais difícil de ser delimitada, ainda que sintamos a necessidade de diferenciá-la daqueles processos artísticos que têm como único fim a criação de um produto artístico para o consumo estético.

Essas diferenciações se fazem ainda mais complicadas pelo fato de que incorporamos no vocabulário dos artistas o termo pesquisa como ferramenta que tenta, na maioria das vezes, ir além da simples delimitação das escolhas estéticas e técnicas que os diferentes grupos e companhias realizam quando criam artisticamente. Por isso, é importante entender como os processos de criação estabelecem relações entre as práticas criativas e as teorias; como o fazer e o pensar podem estar imbricados como parte de um todo que chamamos fazer artístico. Porque fazer teatro é pensar teatro.

Podemos observar que diferentemente de décadas anteriores são inúmeros os grupos artísticos que reconhecem suas práticas como experiências de construção de conhecimento. Pensar deixou de ser, para vários artistas, uma tarefa do outro, isto é, do crítico ou do professor pesquisador. Aceitamos o fazer como prática de pensamento sobre a arte da cena. Isso representa tanto um desafio para o trabalho, como uma forma de particularizá-lo dentro de um estado de coisas que se caracteriza por uma hiperinflação de formatos e modelos onde é difícil realizar distinções.
1.

Professor da Universidade do Estado de Santa Catarina, pesquisador $\mathrm{CNPq}$, diretor do Grupo Experiência Subterrânea. 
Os grupos teatrais costumam fazer em seus projetos e programas de espetáculos referências às suas "pesquisas". Assim, parecem estar reivindicando uma compreensão que não divide pensar e fazer. No entanto, vale a pena refletir se isso expressa um conceito ou é apenas reflexo de uma prática a partir da qual se torna convencional chamar toda criação de pesquisa. Até onde haveria uma compreensão da complexidade das relações entre fazer e pensar, que permita, tanto reivindicar o caráter investigativo dos processos de criação, como reconhecer o valor criativo das pesquisas que nascem no palco?

Apesar de que, em alguns casos o uso dessa terminologia não significa que realmente o trabalho tenha como suporte uma pesquisa sistemática, é correto afirmar que quando se estabelece um processo de criação, seja mais ou menos intelectualizado, são disparados processos de construção de novos conhecimentos. A diferença significativa estará no fato de que este ou aquele artista sistematize esses conhecimentos sob a forma de conceituação do seu fazer criativo. Elaborar conceitos e organizar uma fala sobre a obra é produzir um campo intelectual que desdobra a arte, e seus conceitos, abrindo novas possibilidades de criação, tanto de objetos artísticos como da própria arte como sistema.

A pesquisa como prática associada ao fazer teatral se fez algo tão cotidiano que até os editais de fomento artístico induzem a tal prática. Podemos ver o caso do importante edital da Petrobrás, que na sua versão de 2012 diz que os concorrentes devem apresentar um "plano de pesquisa para um espetáculo inédito, o mais detalhado possível", e continua, "visto que se trata de uma pesquisa, solicitamos que o tema seja informado, bem como os caminhos possíveis para o seu desenvolvimento...”. Já resulta difícil discernir aquilo que nasce como necessidade interna do coletivo de criação, e aquilo que é uma resposta às expectativas das instituições de financiamento.

A vinculação entre fazer e pensar ultrapassa o fórum da academia ou dos artistas, de modo que a realização de pesquisa como elemento constituinte do fazer artístico, repercute tanto no estabelecimento de procedimentos criativos, como resulta na possibilidade da valorização e validação dos resultados artísticos obtidos. Já não é possível separar de forma absoluta essa indução e o discurso de "nossa pesquisa" dos valores atribuídos aos produtos resultantes. Ainda que possamos discutir a íntima e quase indissolúvel relação entre realizar e pesquisar, entre fazer e pensar temos uma dimensão desses processos que deve ser observada menos em seu aspecto expressivo / cognitivo, e mais em seu contexto sócio político. Isso nos obriga a questionar nossos próprios discursos. 
Para analisar os processos criativos e de construção de conceitos, podemos considerar o pensamento de Lev Vygotsky, quem afirma que o desenvolvimento cognitivo está intimamente relacionado ao contexto sócio histórico e cultural onde o sujeito está imerso. Por isso, para o cognocitismo é impossível separar o fazer e o pensar. A experiência social, a interface com os outros só se pode dar no contexto das trocas sociais, o que implica em prática, mas, não pode se dar sem a produção de ideias. Considerando a ideia de que o desenvolvimento cognitivo ocorreria na zona de desenvolvimento proximal, ou seja, o interstício entre o nível de desenvolvimento real do indivíduo e o nível de desenvolvimento potencial, pois é ali que se dariam as interações sociais que, efetivamente, produzem os processos de aprendizagem, impulsionando a capacidade de pensar a partir das realizações do sujeito. Assim, a interação social é fundamental para o desenvolvimento da aquisição ou produção de conhecimento. Neste sentido, os intercâmbios de significados são fundamentais para a produção de pensamento.

A formação da mente é resultado de uma relação dialética entre o fazer e o pensar. Da mesma maneira o vínculo entre prática e teoria no processo criativo deve ser considerado como elemento estrutural do fazer artístico. Quando fazemos arte também estamos compreendendo e decodificando a gramática da linguagem artística. Dessa forma nos apropriamos dos aspectos cognitivos e sensíveis de modo simultâneo, e, eventualmente, quase não podemos diferenciá-los nesse processo. A existência humana é a experiência das relações, somos a partir de nossas relações, pensamos no seio de nossas relações com os outros e com as coisas.

Retornando ao fenômeno do fazer arte, no nosso caso ao "teatrar", ao criarmos procedimentos cênicos e espetáculos, estamos fazendo e pensando o que fazemos. Dessa forma, estamos construindo nosso pensamento sobre a arte do teatro. Nossos processos criativos devem ser compreendidos como parte central do pensamento sobre o teatro como linguagem.

O pesquisador Marco De Marinis identifica na segunda metade do século XIX uma inovação chave que inaugura o teatro moderno, isto é, a ruptura com os modelos teatrais baseados nos tipos, e a introdução da noção da personagem como elemento central das práticas criativas (2005). Esta inovação produziu uma profunda modificação nas relações entre o pensar e o fazer, pois, com o advento da personagem e da noção de composição cênica podemos observar que todo fazer teatral adquiriu características de reinvenção da cena, o que, inclusive, está estreitamente relacionado com o aparecimento da função da direção como elemento chave do teatro moderno. 
A cena moderna, baseada na criação do diretor e dos processos de construção dos atores coloca sempre a tarefa do repensar o teatro como procedimento e como projeto estético. Considerando essa perspectiva podemos observar como pensar e fazer se tornam ações inseparáveis da construção da cena. Já não podemos separar o ato de criação do ato de reflexão de o que seria o teatro. Faz parte da natureza do teatro que fazemos atualmente, pensá-lo, refazendo-o como discurso artístico.

A partir da proposta revolucionária de Marcel Duchamp, quem colocou em crise a separação estanque entre arte e pensamento, com sua proposta de ready made, isto é, a arte como conceito, se tornou impossível aceitarmos a ideia de um fazer artístico que não esteja comprometido com o pensar a arte e seus processos.

O discurso artístico deve ser compreendido como uma fala sobre o mundo da arte. Estamos no reino da metalinguagem. No teatro as circunstâncias de desenvolvimento do século $\mathrm{XX}$, essa premissa se fez ainda mais presente. Por isso, não podemos falar de um fazer artístico que não seja pensar a arte.

Vivendo em um tempo em que é muito difícil identificar diferenças entre construir ideias e construir objetos artísticos, podemos dizer que o pensar também é fazer arte. Atualmente, é difícil tratar de delimitar o que seria a própria arte. Utilizamos de forma instrumental, ideias que nos serviram durante muitos séculos, mas, sabemos que elas já não dão conta em absoluto de delimitar o conceito de arte que realmente opera no campo da cultura. Para facilitar nossa tarefa cotidiana continuamos falando de arte como uma prática de criação de objetos do campo da estética. Mas, desde o advento de diferentes abordagens, como a arte conceitual ou da estética relacional, nos encontramos em um terreno movediço e traiçoeiro. Podemos gostar mais ou menos dessa situação, mas, não podemos desconhecê-la, ou negá-la de forma absoluta sob pena de continuarmos produzindo uma arte (pensamento) que estaria deslocada das relações de construção - fruição - significação, que nos definem como artistas.

Apesar de que, para tranquilidade de muitos de nós artistas, a arte ainda é percebida através dos objetos (quadros, composições ou peças teatrais) pela ampla maioria do público, é fundamental produzir arte considerando que o território das linguagens artísticas se ampliou de forma irredutível. As relações ao redor dos objetos artísticos incluem inevitavelmente, as dimensões conceituais relativas à construção do objeto e também do gesto criativo. Aprofundar a reflexão sobre como podemos compreender a interface entre fazer e pensar é importante para o desenvolvimento do nosso campo de conhe- 
cimento. Isto é particularmente significativo para a intensificação das trocas entre o que parece pertencer ao mundo da academia, e aquilo que habita o espaço da criação.

No entanto, quando abordamos questões relacionadas com o fazer e o pensar em relação aos processos artísticos ainda nos deparamos com pontos de vista que falam no 'pensar' significando um 'refletir' posterior, como uma outra e independente ação. Esta separação que prioriza o 'pensar' antes do 'fazer', permitiria a existência de um 'fazer sem pensar', ou ainda suporia considerar este 'pensar' posterior como uma atividade fundamental para acompanhar aquele fazer. Esta reflexão acabaria por ocupar um lugar não apenas distinto, mas sobre tudo, hierarquicamente superior, ou pelo menos de maior consistência frente à obra resultante do fazer. No caso dos artistas teatrais, é importante lembrar como nossa cultura valoriza a produção de documentos papáveis, de modo que a reflexão que produz resultados escritos facilmente adquire maior valor frente ao trabalho efêmero da cena. Constatar isso não implica dizer que ambas coisas são simplesmente equivalentes. Impossível não reconhecer que têm naturezas distintas. No entanto, pensar ambas ações sem criar uma hierarquia é uma tarefa que nos ajudaria a definir nossa abordagem do fenômeno artístico desde a sua polivalência.

O teatro é um "entre", é um acontecimento que se da entre os artistas e os espectadores, é uma ação compartilhada. Por isso, ele pertence à ordem do experimentado e do lembrado, intercambio cultural, e inscrição na memória (Bergson, 1990). O teatro, arte efêmera, continua reverberando na memória como única hipótese de sobrevivência. Pertence então a uma esfera na qual os sujeitos participantes têm consciência de seu inevitável destino residual. A mera existência do espetáculo dificilmente explica o esforço humano empenhado na realização do projeto teatral, pois, se há uma eficácia possível essa remete à permanência como memória. Há então uma promessa de prática - realização da cena e da recepção - que já anuncia o pensar como componente chave do ato de se fazer teatro, já seja como atores ou espectadores. Pensaremos no espetáculo (nossa prática) porque não nos resta outra opção do que assumir seu papel de objeto (experiência) da memória. Fazer ou pesquisar esse objeto (ato e memória da experiência) é também construir condições para sua repercussão posterior ao ato da presença. Construímos olhares sobre esses objetos e produzimos significados que estão relacionados com a experiência da produção e recepção.

Na filosofia como na arte podemos trabalhar com a ideia do fazer com o sentido de criar ou construir, o que também 
significa refletir. Certamente, para criar ou construir é preciso refletir, isto é, identificar, diferenciar, associar. Mas esse refletir já se constitui em ação criativa. Toda ação está imbricada como reação ao pensamento ou implica em um pensar que operacionaliza a ação.

$\mathrm{O}$ ato artístico busca compreender, e fabricar o mundo através das linguagens artísticas. A obra expressiva não é completamente elaborada de antemão, pois, se transforma ao ser feita, isto é, ao mesmo tempo em que é pensada. A condição dessa reflexão coloca o artista na posição do sujeito que se refaz na sua ação de fazer aquilo que é a arte. Os elementos da linguagem da cena são definidos e utilizados no mesmo momento em que o artista faz e refaz seu pensamento sobre o objeto e seu contexto. Desse modo, o artista não pode simplesmente refletir sobre sua prática, contemplando "seu fazer" de um modo separado e distanciado. Toda vez que o artista pensa seu trabalho o está refazendo.

Ao relacionar o fazer com o pensar podemos explorar a ideia de liminaridade, a partir do que propõe Victor Turner em relação ao ritual. A liminaridade está relacionada com situações ambíguas e limítrofes, ou mais especificamente, de transição entre campos. O teatro é uma experiência definida pela existência de campos em tensão, campos que podem ser transitados pelos sujeitos que tomam parte na cena, dado que existe a abertura de um espaço entre a cena e a condição de expectação, ou seja, o resultado do atravessamento de limiares da vida cotidiana pela operação do ficcional.

O evento liminar produz tensões criativas a partir das quais atores e espectadores podem produzir leituras desses mundos distintos, mas, intimamente conectados. Os deslocamentos de papeis que impõe o comportamento liminar, a promessa da inversão de valores, propiciam vivências nos interstícios de dois mundos. Essas vivências levam o ator a pensar o mundo do espectador e o mundo da cena, como parte do próprio processo de estar em cena. Outra vez retornamos à ideia do pensar como um fazer, e vice versa.

Como o ator tem consciência desses dois mundos pode reconhecer que o mundo da ficção é onde ele domina os acontecimentos, enquanto o mundo real, isto é, a vida na qual o espetáculo é só mais um acontecimento, escapa ao seu controle absoluto. Então o ator pensa esse seu estar (fazer) no mundo da ficção, como uma visitação ao interstício entre ambos mundos. O mais sensível território do teatro está neste entre mundos, ou nessa condição entre o fazer e o pensar. Um fazer que é lúdico, isto é, independe de racionalizações porque é jogo, e um pensar que reorganiza os sentidos do jogo. 
Quando temos uma separação clara e reconhecida facilmente entre o fazer e o pensar, podemos nos sentir em um território seguro. Mas, este será também um território menos vivo. Cada vez que as fronteiras entre o fazer e o pensar se diluem se produzem sensações, experiências e construções intelectuais mais intensas. Na mesma medida o fazer que se multiplica invadindo outros territórios que vão além daqueles tradicionais reservados à produção de artefatos e de imagens. Neste caso, o fazer pode adquirir qualidades que normalmente reconhecemos na produção de conceitos. A imagem da cena como fala conceitual.

As fases que para Turner caracterizam o acontecimento limiar são: o surgimento de fendas, a ebulição das crises, a ação reparadora e a reintegração. Apesar de sua distância como os acontecimentos rituais liminares, o teatro pode abrir fendas no nosso mundo real sob circunstâncias específicas. Estas fendas podem ser reconhecidas no universo individual, isto é, no micro cosmos de atores e espectadores tratados como sujeitos particulares. Identificar as fendas com fenômenos coletivos implica na difícil tarefa de se obter um resultado papável. Antes de falar em uma repercussão social teríamos que pensar a ocorrência das fendas como desdobramento do acontecimento no sujeito e das operações desse que emergem da experiência no teatro. Mas, ainda teríamos que nos perguntar como a fenda é percebida? Seria no próprio fazer ou isso seria da ordem do pensar? No entanto, a hipótese da fenda que permite a visualização de outros fenômenos para além do evento ficcional, implica na percepção de um acontecimento que nos desloca para um terreno no qual será difícil delimitar o que é o fazer e o pensar, dado que nesta fronteira ambas coisas terão um entrelaçamento extremo.

Podemos associar a ideia de fenda com a noção de crise, considerando essa segunda como uma abertura de um espaço dialético. No teatro a crise está representada pelo fato de que o ator se coloca em uma condição instável e arriscada para poder comunicar-se, para propiciar o evento liminar. Ainda que o espectador tenha um comportamento que, via de regra, fuja da crise, e evite o território da insegurança, este pode desfrutar do imprevisível que a cena oferece. É essa hipótese que impulsiona o ator a buscar os lugares extremos e a crise.

A condição limítrofe do ator funciona para o espectador como condição experimental / especular. O ator é aquele sujeito que vai onde o espectador não se aventura, ainda que desejasse fazê-lo. Mas, estar frente a essa viagem do ator aos territórios temidos não se dá sem que possamos perceber uma dupla prática que compromete o pensar e o fazer. O espectador, 
desde seu lugar de público "faz teatro" como o outro polo da cena. De maneira simultânea pensa a cena, pois, sua percepção e ação de recepção, são a elaboração de sentidos da cena.

A criação e a investigação, ou reflexão crítica são atividades inseparáveis e complementarias e definem o fazer artístico como algo cujo pensamento é prático. Como diz o pesquisador espanhol José Antonio Sanchez, "não existe pesquisa sem criação, e a criação sem pesquisa não é arte" '2. Essas são duas forças da construção de conhecimento no campo das artes.

Entender a imbricação entre o fazer artístico e o pensar não deve redundar em uma atitude servil da pesquisa ao fazer artístico. É importante refletir sobre quais são as tramas nas quais estão organizadas as interrelações das diferentes formas do fazer teatral, e como estas se articulam com os processos de construção de pensamento reflexivo. Isso deveria orientar nossa atenção sobre a pesquisa teatral e suas relações com as práticas criadoras.

Considerando o Teatro como uma fala, podemos dizer que ele é sempre um pensar sobre o mundo e sobre si mesmo. Por isso, é preciso investir em abordagens e procedimentos de trabalho que coloquem em discussão a existência de uma divisão taxativa, e certamente simplória, entre artistas e pesquisadores. Mais vale desvendar como estes diferentes campos se interferem mutuamente, do que buscar a especificidade de cada um deles. No entanto, reconhecemos diferenças entre estes dois campos. Portanto, cabe perguntar quais as fronteiras de cada uma dessas ações, com o sentido de descobrir as possibilidades de interpenetrações mútuas.

Uma tarefa que decorre desse ponto de vista é questionar como reconhecer na pesquisa do artista em sua sala de ensaio elementos que sejam comuns aos da formulação de campos conceituais. A partir disso precisamos nos perguntar como relacionar o rigor que se busca com os estudos teóricos, e a livre construção de discursos que caracteriza a arte.

Dado que os processos de criação artística e os fenômenos intelectuais estão vinculados, e se penetram mutuamente, a vivência artística só pode ser compreendida se consideramos que a capacidade de criar implica no aprofundamento dos sentidos de suas criações, e consequentemente, em uma "teoria" dessa criação.

A presença do elemento pessoal, isto é, da vivência, constitui aspecto chave dos processos cognitivos que conformam o campo das artes. A perspectiva dialógica que considera a relação da pesquisa com a criação estabelece um olhar mais acurado para as diversas falas que constituem o sistema teatral tomando as particularidades dos processos individuais e
Afirmação

realizada em sessão do Seminario Internacional Las artes escénicas como práctica de investigación (la transformación de los espacios acadêmicos y artísticos - 1990/2010) 
subjetivos. A arte é elemento de conexão entre o individual e o coletivo, cujos processos de criação são também produção de pensamento. Desta forma, estes são sempre processos de aprendizagem da própria linguagem, de modo que se pode dizer que esta criação é recriação do objeto e do sujeito que fala.

Como diz Caroline Gipps uma criança aprende fazendo e falando sobre o que está fazendo (1999). Um processo criativo no teatro sempre implica em um conjunto de atividades que compromete seus participantes em um ir e vir da sala de ensaios ou de apresentações às discussões sobre as experiências realizadas. Um próprio processo de ensaio se define muitas vezes pelo falar. Onde podemos situar o trabalho da direção se não no exercício do falar e refletir sobre a prática? Esse falar é pensar, mas é um fazer fundamental dos processos de construção artística, é suporte do criar teatro.

Há outro sentido para a pesquisa em arte do que se perguntar sobre vias a partir das quais ambas práticas (pesquisa e criação) se definem? Sem a identificação de como ambas se interferem mutuamente é impossível conceber um pensar que seja fazer. Por isso, as abordagens de ordem filosófica representam uma importante contribuição para as práticas artísticas contemporâneas, sugerindo aproximações ontológicas do fazer teatral, e sugerem "formas de trabalho que propõem um compromisso vinculante, estreitando a distância entre objeto e pesquisador" (CARREIRA/CABRAL, 2006, p.16).

A reflexão filosófica sobre o teatro contribui para o aprofundamento da discussão sobre lugar do teatro na cultura, e as correspondentes repercussões estéticas dessas abordagens. Assim, podemos ir além dos lugares ocupados tradicionalmente pela reflexão ocasional dos criadores ampliando o âmbito do debate sobre os fenômenos do teatro.

A premissa que orienta este trabalho é o da reflexividade da prática artística. O fazer artístico tem como eixo estrutural não só sua prática como a produção de um pensamento que não se organiza a partir da simples contemplação. Este pensamento deve ser entendido como realização prática concreta que é produção de linguagem. No entanto, tanto o ensino como a pesquisa em artes cênicas costumam separar, ainda que dissimuladamente, as práticas da cena da teoria teatral. Consequentemente, nossos cursos universitários organizam seus planos de estudo a partir de áreas práticas e teóricas de modo que nos induzem a aceitar que o pensar pertence a um lugar cuja função fundamental é olhar a experiência prática para se produzir reflexões. Explicar a prática artística tem sido a função da crítica, pois esta tem sido convocada a pensar o fazer como se os que fazem não estivem habilitados a essa tarefa tão complexa. Esse estado de 
coisas tem se alterado rapidamente, mas ainda persiste o problema da separação entre o fazer artístico e a investigação. Isso vem sendo tratado de forma insistente, e, consequentemente conseguimos grandes avanços, ainda que este divórcio não esteja superado. Persistem no âmbito acadêmico importantes tensões entre o fazer e o pesquisar ${ }^{3}$.

A pesquisa em artes cênicas nas universidades expandiu as possibilidades em relação aos processos criativos das artes cênicas com repercussão inclusive na renovação de planos de estudos. Apesar das mudanças pode-se observar que quando a pesquisa em arte é investida de uma formalidade considerada acadêmica, ambas as atividades parecem distanciar-se. A formação universitária tem ampliado as possibilidades do profissional do teatro e tem gerado novas modulações para os processos criadores. Mas, como Biange Cabral e eu afirmamos na introdução do livro Metodologias da Pesquisa em Artes Cênicas:

Esse processo não se deu sem explicitar contradições entre o fazer artístico e os procedimentos acadêmicos tradicionais. Isso fica mais evidente quando refletimos sobre a pesquisa em arte, e em particular, quando nosso assunto é a pesquisa em artes cênicas, uma arte do momento, uma arte que tem a efemeridade como "substância". Basta observar o debate sobre procedimentos de avaliação da produção acadêmica levado a cabo no país nos últimos anos, para se perceber como as duas tradições têm pontos de atrito. Outro signo dessa tensão é o fato de que ainda não temos na universidade brasileira um claro consenso de como instrumentalizar e avaliar trabalhos de conclusão de curso que tenham a forma de objeto artístico. Ainda predomina entre os programas de pós-graduação a valorização do texto escrito como matéria de avaliação. Assim, mesmo quando se aceita o espetáculo como alternativa da dissertação ou da tese, aparece a demanda de um "memorial descritivo" como documento um tanto mais "sólido". Mas, isso ainda carece de um maior desenvolvimento sobre as funções tanto do produto artístico como do documento escrito.

Essa discussão ainda merece uma grande atenção de todos aqueles que estão interessados em desenvolver o campo teatral associado à pesquisa. Isso é ainda mais significativo se consideramos que estamos estreitando as relações entre quem ensina nas universidades e quem faz teatro nos palcos e nas ruas. Estes artistas cada vez mais estão tomando espaços na academia.

Os modos do pensamento universitário têm penetrado os territórios do fazer artístico. Essa hibridação produz tensões entre o impulso da criação - a pesquisa de linguagem -, e os procedimentos "científicos" que caracterizam as normas da academia. Intensifica-se então o mandato da teorização.
Alguns autores apontam a distinção entre o que seria uma pesquisa e a pura especulação. Neste sentido, é interessante observar o que Silvio Zamboni afirma no livro A pesquisa em Arte, opõe a pesquisa ao que ele considera especulação: "o indivíduo que faz especulação está consciente da vacuidade de sua proposta, está solto e descompromissado com qualquer situação que exija uma resposta; ele tenta sem saber o que conseguirá, e ele mesmo não sabe firmemente o que pretende conseguir (...) Por não considerar a especulação como método de pesquisa, não quero dizer que ela não tenha validade no processo global de produção artística. (...) Na ciência, esse tipo de procedimento especulativo e casual tem participação muito mais reduzida do que na arte." (2006: 54) 
Seria preciso teorizar. Nasce o risco de que essa pressão reafirme a separação entre fazer e pensar ainda que em princípio pareça uma aproximação, porque se manifesta a demanda da estruturação de um pensamento organizado que estabeleça relações para além do próprio objeto artístico.

Podemos ocupar esses espaços universitários e continuar produzindo pesquisa no campo das artes cênicas? Como preservar os elementos estruturais do saber artístico, estando inevitavelmente em dois lugares de forma simultânea? Responder essas questões é inventar formas de trabalho que articulem procedimentos com elementos de ambos referentes. A aproximação do teatro à universidade permite que o primeiro aprofunde sua capacidade de registrar suas experiências de criação. Isso repercute na ampliação de reflexões sobre os aspectos técnicos de forma mais metódica. Nos processos de criação o foco é realização e concretização de materiais. Já o registro permite uma distância que organiza o olhar sobre os procedimentos. Esta possibilidade de sistematização favorece que se revisite experiências próprias, confrontando-as com experiências alheias. A análise de procedimentos de criação permite a abertura de novas perspectivas para os processos que associam o fazer com o pensar, como forma de dilatar as relações com diferentes elementos que incidem sobre os processos de criação.

Produzir conceitos é outra dimensão do ato criativo, e é a contracara complementar do fazer. Ainda que o artista não tenha obrigatoriamente que produzir teoria, e por mais caótico que sejam seus processos criativos, sempre há articulação de pensamentos que sustentam a obra artística. Esse é o território a ser explorado para a reflexão sobre metodologias de pesquisa em artes cênicas, considerando que esta pesquisa está estreitamente relacionada com a criação de espaços de diálogo entre as diferentes tramas do fazer teatral.

Para refletir sobre nossa linguagem artística é preciso produzir tensões que cortem transversalmente o eixo criação - fruição - reflexão, pois, este é um o mecanismo através do qual se constroi a arte enquanto campo intelectual. Pesquisar teatro para fabricar novas hipóteses de Teatro. Nossos ensaios ou pesquisas devem nos conduzir à reconstrução nossas noções de o que é o Teatro. Fabricar novas ideias é inerente ao fazer teatro, por isso podemos considerar a realização de experiências criativas como forma de interrogar como a cena reformula seus princípios e suas articulações. É neste lugar que artista e pesquisador se fundem, pois, é ai que se intervém diretamente formulando noções, conceitos e hipóteses, é quando podemos dizer que estamos no território do fazer-pensar. 
BERGSON, Henri. Matéria e memória. São Paulo: Martins Fontes, 1990.

CARREIRA, André e outros (org.). Metodologias de pesquisa em artes cênicas. Rio de Janeiro: 7 Letras. 2007.

DE MARINIS, Marco. En Busca del Actor y del Espectador (Comprender el Teatro II). Buenos Aires: Galerna. 2005.

EISNER, Elliot. The Arts and the creation of mind. New Haven. Yale University Press. 2002

GIPPS, Caroline; MCCALLUM, Bet; BROWN, Margaret. "Primary teachers' beliefs about teaching and learning". In Curriculum Journal, Volume 10, Issue 1, 1999

Textos escolhidos. (Os pensadores). São Paulo: Abril. Cultural, 1980.

ZAMBONI, Silvio. A pesquisa em arte - um paralelo entre arte e ciência. Campinas: Autores Associados, 2006.

ZAYAS DE LIMA, Perla. Presencia y función del discurso científico en el teatro. In Revista Teatro/CELCIT. No 33167. 